\title{
A comparative study of Rural and Urban EFL Secondary school students towards usefulness and liking of English in Punjab, Pakistan
}

\author{
1.Muhammad Nadeem Chohan, 2.Muhammad Saleem Rana \\ Ph.D Scholar at University Of Managment and Technology,Lahore, Pakistan \\ M.Phil Scholar Applied Linguistics, The University of Lahore, Pakpattan Campus.
}

\begin{abstract}
Usefulness and Likings are very important perceptions for learning every subject in the fields of education. As English is an official language taught in Pakistan as compulsory subject. Learning English is skill in Pakistan which is saleable and thought to be very useful by the world of academia. In Pakistan EFL students also love to study English as it is the status symbol and increases candidates significance for job interviews. The study was intended to find out perceptions regarding usefulness and likings of EFL students of secondary schools in Punjab Pakistan. A questionnaire was used to collect data from 180 secondary level EFL students. The study explored important and valuable information on the basis of which it could be stated that the students of intermediate level in Punjab, Pakistan had much inclination for learning English and had positive attitudes towards liking and usefulness of English in their professional development
\end{abstract}

\section{Keyword: Usefulness, Liking, Secondary level Student, Punjab, Pakistan}

\section{INTRODUCTION}

Language is considered as an important instrument for communication. Particularly, different types of communicating ideas are needed in target language for learning language. It requires an important communication in the target language in which speaker's communication is not relevant to the speech but is related to the understanding of communication message and perception (Krashen,1981). Language is a spoken activity for human beings and it is known as self-expression of humans. Language has the primary importance because people generate their personal languages in the development of language that has long life results (UNESCO, 2012).English language is a language that is considered as Lingua Franca, says Crystal (1997, 2003). Ammon (2001) stated that the English language has become the world most useful language for international communication in these days. The speaking and writing ability in English produces different types of opportunities in the modern professional world. In these days, English language is not only useful for native speakers but also for non-native speakers who use it as a second language.

Abbas (1993) and Rahman (1996-2003) have viewed that the role of English language is very important in Pakistani context conducted a survey in Lahore in 1992 which suggests that student's preferred English language over Urdu and their other mother languages in Punjab. She further found out that as an efficient language while other languages are used only for the purpose of conversation with each other.

Tsui and Buton (2000) haven of the view that English is a language which is used as lingua franca in different sectarian and linguistics groups countries like India, Malaysia and Singapore.

In Pakistani context, the English language is considered as the official language .English has a lot importance and is considered one of the highest languages in the Pakistani society (Rahman, 2002). With the usage of some local languages, Urdu is also used for speaking with each other's whereas the documentation is in English. English language provides opportunities to those who can write and speak well. Talaat (2002) states that we require English when we have to talk with other global world.

Sanae Tsuda (2003) conducted a survey research on Japanese student attitudes towards English language learning through responses from all 1st year and 2nd year students at university and described a part of the results of the survey at the 8th International Conference on Cross-Cultural Communication in Hong Kong.

The focus of this study was on the student's attitudes towards English and written comments that has not been included in any previous research paper which expresses that why the students are not interested in studying English. This study compare both the students those who are interested and those who are not interested by examining them through the components of a questionnaire. The research study explores the view that it is very important to produce awareness in students towards English that helps them not only in the utilization of spoken but also helps in the second and foreign language spoken.

DOI: 10.9790/0837-2109062228 $\quad$ www.iosrjournals.org $\quad 22 \mid$ Page


Mansoor (2005) has of the view that Pakistani students, teachers and universities give more value to English as compare to Urdu. They preffer English over Urdu. Atef Al-Tamimi and Munir Shuib (2009) explained in their study that likings of Petroleum Engineering students towards English language learning is very high and their final results showed that these students had much interest in the educational process of English

Hashwani (2008) conducted a research study on motivational factors and experiences that had a strong influence on the attitudes and anxiety level of student's gender wise while they learning English language. This research study attempted to find out the complications of motivational attitudes and anxiety level of students toward English as second language learning in a multilingual context of Pakistani cities like Karachi. It further explored that students had positive attitudes and a high level excitement toward English language learning The overall results stressed that female have higher degree of positive attitudes and motivations as compare to the male. The classroom anxiety level of the students revealed that the high standard deviation regarding anxiety differ from one student to another student.

Alkaff (2013) narrated in a study that the attitudes and perceptions of Foundation Year(FY) students towards English language learning in an institute of English at the English Language Institute (ELI) of King Abdul-Aziz University (KAU) in Jeddah, Saudi Arabia. He is of the view that different researchers tried to know the opinions of the students towards likings of English language learning that whether they think English language learning is difficult or not and where the problems regarding English language learning are present. He examined those areas by which students tried to enhance their English language and fluency and further the usage of English language. This related study explored the way that mostly students have had positive attitudes and likings when they are learning English language the study further explored the problems of students regarding their language learning procedure.

This study has a lot of importance regarding all aspects of language learning. This research study will offer a complete guidance who wants to work in future in the respected line. All those strategies and techniques will be utilized in the future which is not in pure form by eliminating the systematic and technical errors. English language may be a foreign language, but it is multinational in its connotation. This is the major reason that a high degree of research on various aspects of English language goes on in this global village. Gardner (1985) points out those different students have different perceptions and likings about target language groups. He further stated that student's cultures have profound effects on their achievement in the target language.

\subsection{Problems Statement}

In Pakistan EFL students also love to study English as it is the status symbol and increases candidates significance for job interviews. Keeping in mind all these facts of English liking, the researcher decided to conduct this research to investigate the extent of this liking for English language. As this is such an important issue in Pakistan and in all the world that's why the researcher decided to explore it so that it could be used for betterment of people.

\subsection{Objectives}

Following objectives will be addressed in the current study:

1. To find out the perceptions of the students about usefulness and likings of English at secondary level in Punjab

2. To find out the perceptions of the EFL teachers about students attitudes towards English.

3. To find out comparison between rural and urban EFL students' perceptions about usefulness and likings of English in Punjab Pakistan.

\subsection{Research Methods}

\subsubsection{Population}

The population of this research study was all the students of Government Colleges/ higher secondary schools (Intermediate level) in Punjab, Pakistan. The sample for the current study is conveniently selected. 60 English teachers and 120 EFL students of Intermediate level are selected as a sample.

\subsubsection{Research Tool}

A validated questionnaire having Likert Scale is constructed and distributed to collect data from 120 male and female EFL students and 60 Teachers. The questionnaire had two components: the first component was concerned with the usefulness of English Language and the second component will be dealt with the liking of English Language on the part of the students. 
3.1 Table (1) shows Mean, Standard Deviation for the aggregate scores regarding EFL students perceive for usefulness and likings of English language

\begin{tabular}{lcccccc}
\hline \multicolumn{1}{c}{ Variable } & Gender & N & Mean & SD & T & P \\
\hline Usefulness and & Male & 60 & 12.65 & 3.37 & & \\
Likings of English & Female & 60 & 10.49 & 3.61 & 3.52 & $0.000 * * *$ \\
\hline
\end{tabular}

The questions related to finding out EFL students' perceptions for usefulness and likings of English language at secondary level in Punjab, Pakistan.

The statistical results in the above table reveal that the t-value for both male and female students at secondary level is 3.52 which is obviously greater than the standard normal value 1.96. This statistical analysis reveals that the hypothesis about Students (both male and female) have great tendency towards learning English as foreign language with equal consent. The results also indicate that usefulness and likings of English by both male and female students are based on their collective wisdom. They are very much interested in learning English because it is very useful for them in making up of future. P-value ***0.000 which is less than 0.05 indicates highly significant and accepted hypothesis that both male and female tendency is almost the same which clearly means that they have the same objectives of learning English as foreign language.

If compared mean score between male and female students, it is revealed that there is no any significant difference (Male: 12.65 and female: 10.49) which also shows that both male and female consider the same level of likings and usefulness for learning English in their academic course. First thing is that English is an international language being the language of science and technology and international trade. In Pakistan which is a developing country. Here, speaking English is considered respect and symbol of higher status. In competitive examination and for other interviews, speaking with fluency at the time of interview is given special considerations.

But students told during the data collection that they do not find time and environment for speaking English. Rather they are guided and directed by their guardians and teachers to learn by heart the selected material helping them to improve their grading in the final examinations. So their much time is spent on writing assignments Essays, letters and comprehensions and other lessons with their exercises. They do not learn English for communication purposes that is why their communication skills in foreign language is disrupted. Any how some of the students are of the view that they like English because they want to get success in their practical life but unfortunately they do not find competent teachers who could help them out making learning language to speak easier.

Female students were of the view that they also like English but often their parents are unable to send them to far off cities to get higher education due to which they could not have access to good teachers. Resultantly, they could only go with the traditional concept of learning or studying English. But interesting information that was explored from the students both male and female students. They were highly motivated and wanted to keep their knowledge up to date regarding English. The students also revealed their sentiments that help them in getting good jobs, making status in the society and clearing competitive examinations for higher jobs. It is because many of the written tests in higher jobs are given in English and interviews are also conducted in English.

3.2Table 2 shows Mean, Standard Deviation and $t$ - value for the scores of the perceptions of the EFL teachers about students attitudes towards English

\begin{tabular}{ccccccc}
\hline Variable & Gender & N & Mean & SD & T & P \\
\hline Students' attitudes & Male & 30 & 12.66 & 3.29 & & \\
Toward English & Female & 30 & 12.59 & 3.19 & 2.11 & 0.045 \\
\hline \multicolumn{7}{c}{$(\mathrm{df}=118, * * * \mathrm{p}<0.01)$}
\end{tabular}

The questions about the perceptions of the EFL teachers about students' attitudes towards English reveal the statistical results of the data. In the above table, results about teachers' perceptions show that students are bound to study English which keeps their focus on studying English through traditional system. The teachers are of the view that students both male and female have the same objectives to learn English. There are 60 population of the teachers out of which 30 are female teachers and 30 are male teachers who were teaching English at intermediate level for the last 8 to 10 years. Mean score for the male teachers 12.66 and 12.59 respectively having standard deviation of 3.29 and 3.19 respectively. T-test shows a value of 2.11 with 0.045 that is greater than the normal standard value 1.96. The results indicate that both male and female teachers at 
secondary level in Punjab have enormously responded that both male and female students have passive attitudes towards learning English with clear objectives. They told the reason that parents are not mostly educated. They are unable to guide their children at home. They mostly rely on their teachers to provide them proper guidance. Hence, this situation creates a gap between the parents and the teachers which ultimately affects the future planning of their children. P-value 0.045 also reveals that both male and female teachers possess the same at perceptions toward the attitudes of the students for learning English.

Teachers provided valuable information during the survey. For example, they said that due to increase in the private schools, colleges and universities, the rich class sends their children to the institutions where students are given special attention. The teachers and the heads of such institutions ensure their best results. Apart from this, the rich parents afford best teachers at their home for their children. Due to which their children are able to get better marks in English while poor parents are not able to provide such facilitation to their children. So their English remains weak.

The teachers also opened realistic information by saying that at public sector institutions teachers are not well paid and they take their positions as granted. This sluggish attitude matters a lot on the learning outcomes of the learners. Besides this, there is a lack of latest language material to the students. They are provided with audio and visual aids helping them to improve their language fluency and accuracy particularly in public sector schools and colleges. That is why students studying at public sector institutions have lethargic behavior towards learning English.

Another useful information was provided by the teachers about the students that students are informed at private institutions that their parents are will be in contact with their teachers and Heads. This also brings a lot of positive change in the attitudes of the students toward their education. Hence, progress in any subject is subjected to a triangle of teachers, Parents and the students. If any one of them is ignored, the students will not be able to produce effective results in subject.

Last but not the least is that English courses at intermediate/higher secondary/ secondary/graduate levels are very much theoretical. The students spend much of their time in cramming the material. They hardly find time to focus their attention on improving their speaking fluency.

The teachers also accepted the ground breaking reality that they themselves are competent enough to speak English fluently. Such teachers are few and far between available in the institutions. There are only few institutions which properly focus on their teachers and the students to be involved in speaking English interactively.

\subsection{Table 3 shows Mean, Standard Deviation and t- value for the scores of comparison between rural and urban EFL students' perceptions about usefulness and likings of English in Punjab Pakistan

\begin{tabular}{lcccccc}
\hline Variable & Area & N & Mean & SD & T & P \\
\hline Students' Usefulness & Rural & 30 & 12.47 & 2.51 & & \\
\& Likings of English & Urban & 30 & 13.87 & 2.74 & 2.34 & $0.021^{*}$ \\
\hline
\end{tabular}

$$
(\mathrm{df}=118, * * * \mathrm{p}<0.01)
$$

The questions related to obtaining students' responses from rural and urban areas' schools toward usefulness and likings of English describe general output about learning' attitudes of the students .

Comparison in statistics shows that mean score for students in rural areas secondary schools in Punjab is 12.47 with standard deviation 2.51 while mean score for the students studying in urban areas of secondary schools is 13.87 with standard deviation 2.74. This difference shows difference of attitude to the learning of English. It reveals that students in rural areas have no proper interest in learning English. They find their learning environment ineffective and uninteresting.

In addition to that they have to travel a lot reaching their schools because many of the villages are situated far off from the access of the people. Students living in rural areas are not much inclined toward speaking English. They usually depend on their forefathers occupations and most of the students after the completion of their secondary education take up their fathers' profession and start their own business. Hence their behavior is made up of less supporting environment in the surrounding of rural areas. They don't like English because their life is not more dependent on learning English.

It is plus point for them that they find internet facility available in almost all the cities of Punjab, Pakistan. this facility helps them to collect new information and lectures, online classes, language courses etc. They have the best opportunities to improve their speaking fluency in English. Moreover, more and more experienced and competent English teachers are moved towards urban areas in search better opportunities. They prefer to teach and reside in urban areas. 
It is also revealed that attraction of finance also incites the good teachers to live in urban areas. Apart from this, parents also prefer to send their brilliant children in big cities to get quality of education.

In table statistical results reveal that students are studying in rural areas have less competent teachers in their schools to teach English. The teachers in rural areas have different purpose of teaching English. This variable is also putting effects on students' forming of objectives toward learning English. Most important thing in the rural secondary schools in Punjab is that there are very less facilities for the teachers and the students. Even students have very poor seating arrangement in their classes. They have no proper white boards to write. The number of students in higher secondary schools is also very small. This situation also lessens the interest of the teachers teaching English.

The above interpretation of the statistical results, shows that the students in the urban areas are seen more active as compare to students in the rural areas. Further qualitative pieces of information are discussed in detail in the next chapter.

\subsection{Phase I}

\section{DISCUSSION}

Keeping in mind the statistical results of the collected data and their interpretations it was extracted that students have positive perceptions toward learning and speaking English as foreign language. As English is an official documents language and in educational institutions from class one to graduation, English is taught as compulsory subject but it is matter of great sorry that many students (girls or Boys) have been unable to learn English as much as to be able to speak with good fluency. It was also observed that there was slight difference of learning English between male and female students at higher secondary level. First, the ratio of literacy among girls is lower as compare to male students. The reason is that the girls particularly in rural areas have to face problems like there are only few institutions situated in rural areas where higher education is offered. Hence in such higher secondary institutions, good teachers are not available. Resultantly, they could not have proper guidance about why they should be learning English. However, male students can travel by themselves to the far off colleges to have access to getting further education. Hence they look around to get proper guidance and are able to decide about why they should work for improving their English?

But students told during the data collection that they do not find time and environment for speaking English. Rather they are guided and directed by their guardians and teachers to learn by heart the selected material helping them to improve their grading in the final examinations. So their much time is spent on writing assignments Essays, letters and comprehensions and other lessons with their exercises.

One thing which was observed in common among boys and the girls was that they were equally seen interested with having same craze of learning English. In Pakistan English is considered a symbol of respect as it is used by those who are politicians, business men, CSP officers, Army Officers and Judges etc. Hence, importance learning English to write and speak is increased. The students in Pakistan particularly after their graduation tend to appear in the competitive examinations and look for better prospective.

The current study also resembles another study which was made earlier by Atek, et al. (2012) considered the role of English as a crucial to economic, social and cultural competitiveness because it increases the social and cognitive growth of a person. They resulted that student's mastery in English language not only help them in their studies but also help them in getting better jobs in their society. This study explored only the importance of English but the current study is conducted to examine the perceptions of the students towards learning to speak English. In the same vein, Aggarwal (1995) was of the view that a person who have a command over English language can best communicate in English. He thought that lack command over English can causes many problems regarding communication and expressing his or her ideas fluently in English. So after sixty years of independence, now Pakistanis considered themselves better in English than that of independence time. Pakistan new policies are in the favor of the dominancy of English language in the country.

\subsection{Phase II}

Findings of the phase II revealed that teachers had difference of opinions about students' attitudes regarding studying English. They were of the view that the both types of the students whether they belonged to rural or urban areas of institutions, had to keep their focus on studying English through traditional system. They (both male and female) have the same objectives to the learning English. Difference is to be found only in their attitudes. As the population, approached in this study for the collection of the data, were the teachers having at least 8-10 years of experience teaching in Rural and urban Higher secondary Institutions. Hence their information provided by them was very significant which indicated that both male and female students' attitudes in rural institutions towards learning English were found passive. 
The reasons were also explored that in rural areas students' parents were mostly not educated. Hence they are unable to guide their children at home. They rely on their teachers in maximum to provide them proper guidance. Hence, this situation creates a gap between the parents and the teachers which ultimately affects the future planning of their children. P-value 0.045 also reveals that both male and female teachers possess the same at perceptions toward the attitudes of the students for learning English.

Another useful information was provided by the teachers about the students that students are informed at private institutions that their parents are will be in contact with their teachers and Heads. This also brings a lot of positive change in the attitudes of the students toward their education. Hence, progress in any subject is subjected to a triangle of teachers, Parents and the students. If any one of them is ignored, the students will not be able to produce effective results in subject.

Differences in attitudes on gender based, has not been only the matter of performances in Pakistan but it has been an international phenomenon too. Hence increasing use of information communication technology is bringing positive change in the students' attitudes towards learning English for connecting themselves into the globalized web so that they may be the part of that international community.

\subsection{Phase III}

Third phase provides comparison revealed students' own responses to explore their perceptions belonging to institutions of rural and urban areas towards usefulness and likings of English as foreign language. This phase also provided general output of opinions about learning attitudes of the students. Differences of perceptions of their own between rural and urban (male and female) students indicated that students in rural areas revealed themselves as having no proper interest and likings towards learning English. When their observations were taken about this phenomenon, they described that they prefer to have education in their own national language Urdu as compare to learning English. They indeed expressed their patriotic passions. They also told that all competitive examinations and even many federal and provincial departments conduct their tests for recruitment purposes in English language. They further explained that speaking English is not real criterion to ensure competency. They said that in this many intelligent students do not know English well. Hence, such students are left behind and only those students are selected who know English.

In rural areas most of the people do not like English medium of instruction because they liked to get education in Urdu medium of instruction.

In contrary to the students studying in higher secondary institutions, the students of intermediate level of the urban areas are very active. An important information extracted from the students revealed that the teachers and the students in cities and particularly big cities are well aware of the significance of the knowledge of foreign language particularly English. They have opportunities in their access to get proper language courses in addition to the classes they attend their schools or colleges. They attend regular courses by the competent teachers who are fluent in speaking English. Hence, regular contact with their teachers in using foreign language removes their hesitation. Apart from this in urban areas, the students are more inclined to speak English or at least they code switch and codes mix whenever they meet one another. The students also state their own personal observation and experience that they are properly guided by their seniors and erudite teachers for future prospective. Hence after the accomplishment of their education they set their goals for which English plays an important role in the realization of their dreams.

The survey of this study further revealed that proficiency in English is the dream of each and every student. Even if they fail in this subject or get success. A study in discussed in the literature has cleared this fact as follows:

\section{CONCLUSION}

The study explored important and valuable information on the basis of which it could be stated that the students of intermediate level in Punjab, Pakistan have much inclination for learning English and have positive attitudes towards liking and usefulness of English in their professional development. The current also supports and captures the findings of the other earlier studies to put forward suggestion in the conclusion like: Another research study conducted by Graff (1985) resulted that language is helpful in all perspective of students learning .By the use of language students in a classroom learn much of the information about language learning skills and language culture. He further clarified the idea that language helps students for better understanding and communication and also helps them in sharing their ideas and experiences with other persons. $\mathrm{He}$ concluded that different types of physical, cultural, emotional and psychological development and growth are the major results of language learning. The process of learning that starts from impressions to thoughts is the result of experts in language learning. He further explore the idea that language learner must be accurate, meaningful and fluent. A teacher must be used different psychological, social and cultural in their teaching 
learning process. For successful learning of language the interrelation of different factors like cognitive, affective and psychomotor are very necessary.

The Importance of English language in Pakistan is very important. The usage of English in Pakistan is considered very high. As English language is considered a power symbol for elite class and it has an important influence on the socio economic aspects of Pakistani people. (Ashraf, 2006).

\section{REFERENCE}

[1] Abbas,S. (1993). The power of English in Pakistan. World Englishes 12(2), pp,147-56.

[2] Alkaff, A.A. (2013). Students "e Attitudes and Perceptions towards Learning English. Arab World English Journal online, Vol.4(2), pp 106-121

[3] Al-Tamimi, A., \& Shuib, M. (2009). Motivation and attitudes towards learning English: A Study of Petroleum Engineering Undergraduates at Hadhramout. GEMA Online Journal of Language Studies, 9 (2), 15.

[4] Ammon, U.(2001).The Dominance of English as a Language of Science:Effects on Other Languages and Language Communities. Berlin; Newyork: Mounton de Gruyter.

[5] Crystal, D (1997,2003) English as a Global Language. Cambridge University Press.

[6] Krashen, S.( 1981). Second Language Acquisition and Second Language Learning. Pergamon Press Inc. California.

[7] Gardner, R.C. (1985). Social psychology and second language learning: The role of attitude and motivation. London: Edward Arnold.

[8] Hashwani, M. S. (2008). Students ${ }^{\text {ee }}$ attitudes, motivation and anxiety towards English language learning. Journal of Research and Reflections in Education, 2(2).

[9] Mansoor, S.(2005). Language planning in Higher Education: A case study of Pakistan. Karachi: Oxford University Press

[10] Martínez, D.U, Pérez, J.G. \& Fernández, D.M. (2013). Attitudes of Mexican American Students towards Learning English as a Second Language in a Structured Immersion Program. Porta Linguarum. pp.205221

[11] Rahman, T.(1996). Language and politics in Pakistan. Karachi: Oxford University Press.

[12] Rahman, T.(2002). Language Teaching and Power in Pakistan. Paper presented at World Congress on Language Policies. Barcelona,16-20 April2002.

[13] Talaat, M (2002). The Form and Functions of English in Pakistan. Unpublished Doctoral thesis, Bahuddin Zakariya University, Multan. E-prints. hec.gov.pk /1631/1/1191.HTM.

[14] Tsuda, S. (2003). Attitudes toward English Language Learning in Higher Education in Japan: Raising Awareness of the Notion of Global English. Intercultural Communication Studies XII-3.

[15] Tsui, A.B.M. and Buton, D. (2000). The discourse and attitudes of English Language Teachers in Hong Kong. World Englishes. 19(3):287-303. www0.hku.hk/.../The_discourse_and_attitudes_of_English _language.

[16] UNESCO. (2012). Why language Matters for the Millennium Development Goals. Bangkok. 